\title{
Effect of fortification on the osmolality of human milk
}

M De Curtis, M Candusso, C Pieltain, J Rigo

This work was presented in part at the European Society for Pediatric Research Meeting in Belfast, September 13-16, 1998

Neonatal Unit University of Liège Hôpital de la Citadelle CHR Citadelle 4000 Liège

Belgium

M De Curtis

$M$ Candusso

C Pieltain

J Rigo

Istituto

Materno-Infantile

University of Palermo

Italy

M De Curtis

Correspondence to:

Professor J Rigo.

Email: J.Rigo@ulg.ac.be

Accepted 7 April 1999

\begin{abstract}
Aim-To evaluate the effect of fortification on the osmolality of human milk.

Methods-The osmolality of 47 samples of human milk was determined at baseline, just after, and 24 hours after supplementation with five different human milk fortifiers (HMF) at $4^{\circ} \mathrm{C}$.
\end{abstract}

Results-Ten minutes after HMF supplementation the osmolality of human milk was significantly higher than the sum of the respective values of $\mathrm{HMF}$ dissolved in water and human milk, measured separately at baseline $(p<0.0001)$, with the exception of the HMF containing only proteins. After 24 hours a further increase in osmolality was observed. Linear regression analysis showed that total dextrin content $(r=0.84)$ was the main determinant of the increase.

Conclusions-Human milk and HMF interact to induce a rapid increase in osmolality higher than would be expected from composition alone. This rise could be explained by the amylase activity of human milk, inducing hydrolysis of the dextrin content of HMF, leading to small osmotically active molecules of oligosaccharides. The high osmolality of fortified human milk should be considered in the nutritional management of preterm infants.

(Arch Dis Child Fetal Neonatal Ed 1999;81:F141-F143)

Keywords: human milk; fortifiers; osmolality

For the feeding of neonates, human milk is nutritionally better than formula milk and provides biologically important non-nutrients, such as immunoglobulins, non-antibody mediated immune factors, digestive enzymes, growth factors and hormones which may promote growth and development. ${ }^{1}$ By providing her milk, the mother is also involved in her infant's care and emotional bonding is en-

Table 1 Macronutrient composition of human milk fortifiers (per $100 \mathrm{~g}$ of powder)

\begin{tabular}{llllll}
\hline & $\begin{array}{l}\text { Gallia } \\
\text { Peptides } \\
\text { (Gallia) }\end{array}$ & $\begin{array}{l}\text { Eoprotin } \\
\text { (Milupa) }\end{array}$ & $\begin{array}{l}\text { FM-85 } \\
\text { (Nestlé) }\end{array}$ & $\begin{array}{l}\text { Enfamil } \\
\text { (Mead } \\
\text { fohnson) }\end{array}$ & $\begin{array}{l}\text { Nenatal } \\
\text { BMF } \\
\text { (Nutricia) }\end{array}$ \\
\hline $\begin{array}{lllll}\text { Protein }(\mathrm{g}) \\
\text { Fat (g) }\end{array}$ & 82.5 & 20.1 & 18.5 & 18.3 & 23.8 \\
Carbohydrate (g) & 1.4 & 0.6 & 0.5 & 1.5 & 0 \\
Lactose(g) & 0.2 & 70 & 70 & 71 & 65.3 \\
Dextrines(g) & 0 & 70 & 69 & 17.2 & \\
Na (mg) & 8 & 67 & 540 & 181 & 65.3 \\
K (mg) & 10 & 80 & 230 & 400 & 133 \\
Ca (mg) & 2460 & 1250 & 1020 & 2300 & 2035 \\
Mg (mg) & 37 & 70 & 40 & 26 & 200 \\
P (mg) & 1080 & 850 & 680 & 1170 & 1360 \\
Cl (mg) & 21 & 500 & 375 & 460 & 235 \\
\hline
\end{tabular}

hanced. However, human milk may fail to meet the nutritional requirements of very low birthweight infants: protein content may be too low to permit adequate growth, ${ }^{23}$ the low sodium concentration may lead to hyponatraemia, ${ }^{4}$ and the amounts of calcium and phosphorus are below the intake required to allow fetal rates of bone mineral accretion. ${ }^{5-6}$ This has led to the development of human milk fortifiers (HMF) which increase the nutritional content of human milk by adding protein, energy, and minerals.

Recently, Jocson et al found that the storage of human milk supplemented with a fortifier (Enfamil Human Milk Fortifier) for 72 hours increased osmolality by about $4 \% .{ }^{7}$ They also discussed the possible action of bacterial growth. However, the energy in fortifiers is primarily provided by dextrins, which, acted on by breast milk amylase, could be transformed into glucose with a consequent increase in osmolality.

This study aimed to evaluate changes in the osmolality of human milk after supplementation with several HMFs, each of a different composition.

\section{Methods}

Osmolality was determined in triplicate using an Advanced Clinical Osmometer (Advanced Instruments, MA USA) based on freezing point. Forty seven samples of expressed fresh human milk, stored at $-20^{\circ} \mathrm{C}$, from mothers of term infants who had given their consent, was thawed using tepid water just before examination. The chemical composition of the five fortifiers is shown in table 1. Gallia Peptide (Gallia France) (HMF1) contains almost exclusively whole proteins; Eoprotin (Milupa Germany) (HMF2) contains whole protein, dextrin and minerals; FM-85 (Nestlé Vevey Switzerland) (HMF3) contains hydrolysed proteins, dextrin and minerals; Enfamil Human Milk Fortifier (Mead Johnson, USA) (HMF4) contains proteins, lactose, dextrins, glycerophosphate and minerals; Breast Milk Fortifier (Nutricia, The Netherlands) (HMF5) contains proteins, dextrin, glycerophosphate and minerals.

Human milk was fortified with HMF at different concentrations: $2 \%$ with HMF1, 2.5 with $\mathrm{HMF} 2,5 \%$ with HMF3 and $4 \%$ with HMF 4 and HMF5. These concentrations are in the range most frequently used in neonatal units.

The osmolalities of HMF dissolved in water, at the same concentrations as indicated above, and of various samples of thawed fresh human milk, were determined separately before and 
Table 2 Changes of osmolality (mosmol/kg $\mathrm{H}_{2} \mathrm{O}$ ) of human milk (HM) after supplementation with different human milk fortifiers (HMF) at various concentrations; (Values are expressed as mean (SD))

\begin{tabular}{lllllll}
\hline & $N=$ & $H M$ & $H M F$ & $\begin{array}{l}\text { HM+HMF } \\
\text { (theoretical) }\end{array}$ & $\begin{array}{l}\text { After 10 } \\
\text { minutes }\end{array}$ & $\begin{array}{l}\text { After 24 hours } \\
\text { at } 4^{\circ} \mathrm{C}\end{array}$ \\
\hline HMF1 & 6 & $297(8)$ & $34(1)$ & $330(8)$ & $331(12)$ & $338(12)^{\star} \dagger$ \\
HMF2(2.5\%) & 10 & $291(15)$ & $45(2)$ & $336(14)$ & $350(13)^{\star}$ & $371(16)^{\star}+$ \\
HMF2(5\%) & 7 & $283(9)$ & $88(2)$ & $371(8)$ & $395(12)^{\star}$ & $436(21)^{\star}+$ \\
HMF3(2.5\%) & 4 & $279(10)$ & $38(1)$ & $317(1)$ & $335(14)^{\star}$ & $363(11)^{\star}+$ \\
HMF3(5\%) & 6 & $281(9)$ & $72(4)$ & $354(7)$ & $385(12)^{\star}$ & $449(16)^{\star}+$ \\
HMF4(4\%) & 7 & $284(7)$ & $94(2)$ & $377(9)$ & $401(10)^{\star}$ & $408(10)^{\star}+$ \\
HMF5(4\%) & 7 & $284(6)$ & $77(2)$ & $361(8)$ & $388(10)^{\star}$ & $406(13)^{\star}+$ \\
\hline
\end{tabular}

${ }^{\star} \mathrm{p}<0.01$ vs theoretical osmolality; $\nmid \mathrm{p}<0.01$ vs values of osmolality after 10 minutes from fortification. pressed as mean and $95 \%$ confidence interval is shown in table 3. With HMF1, only a relatively small, late increase was observed: 6.9 (2.3) $\mathrm{mosmol} / \mathrm{kg} \mathrm{H}_{2} \mathrm{O}$. For $\mathrm{HMF} 2$ and $\mathrm{HMF}$, an early $\left(\mathrm{T}_{1}-\mathrm{T}_{0}\right)$ and late $\left(\mathrm{T}_{2}-\mathrm{T}_{1}\right)$ increase in osmolality was directly proportional to the $\mathrm{HMF}$ concentration, and the late increase was twice that of the earlier one. By contrast, supplementation of human milk with HMF4 and HMF5 induced an early increase in osmolality that was significantly higher than the later one.

Linear regression analysis showed that total dextrin content $(r=0.84)$ rather than carbohydrate content $(r=0.75)$ was the main determinant of the total osmolality increase $\left(T_{2}-T_{0}\right)$. Mean amylase activity in human milk was similar before (+1737 (474) U/1) and 24 hours after the addition of HMF (1644 (460) U/1). determined just after fortification (about 10 minutes) $\left(T_{1}\right)$, and after storing the samples in a refrigerator for 24 hours at $4^{\circ} \mathrm{C}\left(\mathrm{T}_{2}\right)$, to determine the effect of mixing and storage.

Amylase activities were measured $^{8}$ in 18 samples of pasteurised human milk at baseline and 24 hours after fortification, to show the effect of storage.

Data are expressed as mean (SD). Student's paired $t$ test was used for statistical evaluation. A p value of $<0.01$ was taken as the level of significance. Linear regression analysis was used to assess the relation between dextrins and carbohydrate content of fortifiers and the osmolality increase in human milk after supplementation.

\section{Results}

The osmolality of human milk and HMF dissolved in water was similar before and after storage at $4^{\circ} \mathrm{C}$. After fortification with $\mathrm{HMF} 1$, osmolality at $T_{1}$ was similar to the theoretical value $\left(\mathrm{T}_{0}\right)$. In contrast, the osmolality of human milk fortified with all other HMF (HMF2 to HMF5) $\left(T_{1}\right)$ was significantly higher than the sum of the respective values of $\mathrm{HMF}$ dissolved in water and human milk $\left(\mathrm{T}_{0}\right) \quad(\mathrm{p}<0.0001)$ (table 2). The increase of osmolality after mixing was proportionally related to the rise of concentration of $\mathrm{HMF} 2$ and HMF3 (2.5 to $5 \%)$.

After 24 hours at $4{ }^{\circ} \mathrm{C}\left(\mathrm{T}_{2}\right)$, the osmolality of fortified human milk was significantly higher than that observed just after reconstitution $\left(\mathrm{T}_{1}\right)$. This increase in osmolality was also present with HMF1 and varied, when all the groups were considered, from 6.9 (2.3) to 63.8 (10.7) $\mathrm{mosmol} / \mathrm{kg} \mathrm{H}_{2} \mathrm{O}$.

The difference in osmolality of fortified human milk between $T_{1}-T_{0}$ and $T_{2}-T_{1}$, ex-

\section{Discussion}

We have shown that the addition of most HMF to human milk induces a rapid and clinically significant increase in osmolality. This effect is evident with all the HMF with the exception of HMF1 which contains only proteins. An additional effect dependent on the HMF used was also observed during storage at $4^{\circ} \mathrm{C}$ for 24 hours.

Recently, Jocson et al reported a mean osmolality value for human milk, after fortification with Enfamil HMF, of $408 \mathrm{mosmol} / \mathrm{kg}$ $\mathrm{H}_{2} \mathrm{O}$, and measured a $4 \%$ increase after 72 hours of storage. This value of osmolality is not dissimilar from the 401 and $408 \mathrm{mosmol} / \mathrm{kg}$ $\mathrm{H}_{2} \mathrm{O}$ we found in human milk with the same fortifier 10 minutes and 24 hours after supplementation, respectively. The authors of that study found that the increase in osmolality could not be attributed to nutrient degradation following bacteriological growth.

In contrast, the amylase activity of human milk may explain the rapid and continuous increase in osmolality after fortification as well as the relation observed between osmolality and the dextrin content.

Carbohydrate distribution varied in the different HMF. For instance, carbohydrates in HMF4 are made from lactose (24\%), mineral sources (glycerol from calcium glycerophosphate, gluconate and citrate) (20\%), and corn syrup (56\%); its dextrose equivalent (defined as reducing power of a hydrolysate compared with that of anydrous dextrose) is 24 and about $5 \%$ of dextrin linkages are similar to that of corn starch. In HMF2 carbohydrates are represented exclusively by dextrins.

Table 3 Difference between osmolality values (mean and $95 \%$ confidence interval) of human milk after supplementation with different HMF at various concentrations observed at $T_{2}$ (24 hours after reconstitution), $T_{1}$ ( 10 minutes after), and $T_{0}$ (theoretical osmolality)

\begin{tabular}{lllll}
\hline & $N=$ & $T_{1-} T_{0}$ & $T_{2-} T_{1}$ & $T_{1-} T_{0}$ vs $T_{2-} T_{1}$ \\
\hline HMF1 & 6 & $0.33 ;(-4.1$ to 4.8$) ; \mathrm{p}<0.86$ & $7.2 ;(3.7$ to 10.6$), \mathrm{p}<0.005$ & $\mathrm{P}=0.02$ \\
HMF2 $(2.5 \%)$ & 10 & $13.2 ;(23$ to 70$), \mathrm{p}<0.001$ & $21.5 ;(13.6$ to 29.3$), \mathrm{p}<0.001$ & $\mathrm{P}=0.01$ \\
HMF2(5\%) & 7 & $23.4 ;(17.5$ to 29.3$), \mathrm{p}<0.001$ & $42 ;(29.7$ to 54.3$), \mathrm{p}<0.001$ & $\mathrm{P}=0.003$ \\
HMF3(2.5\%) & 4 & $17.5 ;(-1.3$ to 36.3$), \mathrm{p}=0.06$ & $28.3 ;(21.7$ to 34.8$), \mathrm{p}<0.001$ & $\mathrm{P}=0.25 \mathrm{NS}$ \\
HMF3(5\%) & 6 & $31.5 ;(22.9$ to 40.1$), \mathrm{p}<0.001$ & $63.8 ;(52.6$ to 75.0$), \mathrm{p}<0.001$ & $\mathrm{P}=0.002$ \\
HMF4(4\%) & 7 & $24 ;(21.6$ to 26.4$), \mathrm{p}<0.001$ & $6.9 ;(4.8$ to 9$), \mathrm{p}<0.001$ & $\mathrm{P}<0.0001$ \\
HMF5(4\%) & 7 & $26.7 ;(23.2$ to 30.2$), \mathrm{p}<0.001$ & $18.1 ;(14.7$ to 21.5$), \mathrm{p}<0.001$ & $\mathrm{P}<0.001$ \\
\hline
\end{tabular}

Osmolality values are expressed in mosmol/ $\mathrm{kg} \mathrm{H} \mathrm{H}_{2} \mathrm{O}$. 
The amylase in human milk is an alpha amylase that hydrolyses starch and dextrins. ${ }^{9}$ However, its activity has little specificity for the $\alpha$ 1-4 linkages in the vicinity of the $\alpha$ 1-6 branching point. ${ }^{10}$ The amylase in human milk is relatively resistant to heat, and to pasteurisation specifically. ${ }^{11}$ Hamosh et al showed that about $95-100 \%$ of initial activity was present after 24 hours of storage at $15-25^{\circ} \mathrm{C} .{ }^{11}$ Similar data were observed in the 18 samples of pasteurised human milk which we examined before and after 24 hours. Therefore, the fortification of human milk may lead to oligosaccharide production, depending on carbohydrate composition of HMF (containing molecules of carbohydrate of different lengths, such as small molecules of glucose, maltose, maltotriose, glucose tetramers as well as a quantity of oligosaccharides with more than 20 units of glucose) and on the $\alpha 1-4: \alpha 1-6$ linkage ratio. Thus the rise of osmolality observed in human milk supplemented with HMF can be explained by the fact that polysaccharides, present in the HMF, are broken down into their constituent mono- and oligosaccharides and the difference observed between the various HMF could be related to the different carbohydrate content and the use of dextrins of different origin and equivalent glucose content. This could also explain why some fortifiers, such as HMF4 and HMF5, induce a relatively early increase in osmolality, while HMF2 induces a late increase. The effect of storage $\left(\mathrm{T}_{2}-\mathrm{T}_{1}\right)$ on osmolality was smaller with $\mathrm{HMF}_{1}$ containing only proteins, and with $\mathrm{HMF}_{4}$ which had the lowest content of dextrins compared with the other fortifiers. The late increase was close to methodological error and was not clinically significant.

In recent years, there has been a dramatic increase in the practice of fortifying breast milk, to give to low birthweight infants the nutrients and other biologically important factors contained in human milk. ${ }^{12}$ The addition of a fortifier to breast milk has many potential advantages, including improved growth and bone mineralisation as well as a reduction in the incidence of hyponatraemia. Nevertheless, a lower weight gain was observed in preterm infants fed fortified human milk compared with those fed preterm formula. ${ }^{13}$ Very low birthweight infants, fed fortified human milk, may develop abdominal distension, reduced gastric emptying, frequent stools, and more rarely, diarrhoea. The supplementation, therefore, often has to be reduced or abandoned altogether, with the attendant reduction in nutrient intake and of growth. Thus the considerable increase in osmolality of fortified human milk, compared with preterm formulas (about $300 \mathrm{mosmol} / \mathrm{kg} / \mathrm{H}_{2} \mathrm{O}$ ) could be partially responsible for the slower growth rate in very low birthweight infants fed HMF rather than preterm formula.

An association between hyperosmolar preparations (higher than 400 mosmol/ $/ \mathrm{kg} \mathrm{H}_{2} \mathrm{O}$ ) and necrotising enterocolitis has been reported. ${ }^{14} \mathrm{In}$ a study of 275 preterm infants, Lucas et al found that, compared with control infants fed human milk, the fortified group showed an increased incidence of necrotising enterocolitis (5.8\% compared with $2.2 \%$; $=0.12) .{ }^{15} \mathrm{Al}-$ though this difference was not significant, they suggested that a larger study would be required to detect a two-to threefold increase in incidence at the 5\% significance level.

In conclusion, the use of human milk fortifiers increases osmolality more than would be expected from composition alone. To improve human milk feeding in very low birthweight infants, it is important to produce new fortifiers with a lower propensity to increase osmolality, but able to assure good growth, and to avoid the side effects responsible for the reduction in nutrients supplied by enteral feeding.

We thank Professor Salvatore Auricchio for helpful comments.

1 Lucas A, Morley R, Cole TJ, Lister G, Leeson-Payne C. Breast milk and subsequent intelligence quotient in children born preterm. Lancet 1992;39:261-4.

2 Senterre J, Voyer, Putet G, Rigo J. Nitrogen, fat and mineral balance studies in preterm infants fed bank human milk, a human milk formula, or a low birth weight infant formula. In: Baum JO, ed. Human milk processing, fractionation, In: Baum JO, ed. Human milk processing, fractionation, Nutrition Workshop Series Vol 3. New York: Raven Press, 1983:102-11.

3 Gross SJ, David RJ, Bauman L, Tomarelli RM. Nutritional composition of milk produced by mothers delivering preterm. F Pediatr 1980; 96:641-4

4 Al-Dahhan J, Haycock GB, Nichol B, Chantler C, Stimmler L. Sodium homeostasis in term and preterm neonates. III. Effect of salt supplementation. Arch Dis Child 1984;59:945-50

5 Senterre, Putet G, Salle B, Rigo J. Effects of vitamin D and phosphorus supplementation on calcium retention in preterm infants fed banked human milk. 7 Pediatr 1983;103:305-7.

6 Ziegler EE, Biga RL, Fomon SJ. Nutritional requirements of the premature infant. In: Suskind RM, ed. Texbook of pediatric Nutrition. New York: Raven Press, 1981:29-31.

7 Jocson MAL, Mason EO, Schanler RJ. The effects of nutrient fortification and varying storage conditions on host ent fortification and varying storage conditions on host
defense proprieties of human milk. Pediatrics defense proprietie

8 Winn-Dean, David H, Sigler G, Chavez R Development of a direct assay for alpha-amylase. Clin Chem 1988;34:20059

9 Jones JB, Mehta NR, Hamosh M. $\alpha$-amylase in preterm human milk. $\mathcal{F}$ Pediatr Gastroenterol Nutr 1982,1:43-8.

10 Fomon SJ, ed. Carbohydrate. In: Nutrition of normal infants. New York: Mosby Year Book, Inc, 1993:177.

11 Hamosh M J, Henderson TR, Ellis LA, Mao JI, Hamosh P. Digestive enzymes in human milk : stability at suboptimal storage temperatures. Pediatr Gastroenterol Nutr 1997;24:38-43.

12 McClure RJ, Chatrath MK, Newell SJ. Changing trends in feeding policies for ventilated preterm infants. Acta Paedifeeding policies for

13 Putet G. Energy. In: Tsang RC, Lucas A, Uauy R, Zlotkin S, eds. Nutritional needs of preterm infants. New York: Williams eds. Nutritional needs of pret

14 Book LS, Herbst JJ, Atherton SO, et al. Necrotizing enterocolitis in low birth weight infants fed an elemental formula. F Pediatr 1975;87:602-5.

15 Lucas A, Fewtrell MS, Morley R, et al. Randomised outcome trial of human milk fortification and developmental outcome in preterm infants. Am 7 Clin Nutr 1996;64:142-51. 